\title{
Gold-Catalyzed 1,2-Migration of Silicon, Tin, and Germanium en route to C-2 Substituted Fused Pyrrole-Containing Heterocycles
}

\author{
Ilya V. Seregin and Vladimir Gevorgyan \\ Department of Chemistry, University of Illinois at Chicago, 845 West Taylor Street, Chicago, Illinois \\ 60607-7061
}

\section{Abstract}

An efficient method for the synthesis of fused pyrroloheterocycles from diverse propargyl-substituted heterocycles in the presence of Au-catalyst has been developed. The cascade transformation proceeds via alkyne-vinylidene isomerization with concomitant 1,2-shift of hydrogen, silyl and stannyl groups. Remarkably, it was also shown that previously unknown 1,2-migration of a germyl group upon alkyne-vinylidene rearrangement occurs under these reaction conditions. This method allows for mild and efficient synthesis of diverse $\mathrm{C}-2$ substituted $\mathrm{N}$-containing heterocycles.

Alkyne-vinylidene isomerization is a mechanistically interesting ${ }^{1}$ and synthetically useful transformation. ${ }^{2}$ For example, McDonald used this transformation as the key step in efficient synthesis of heterocycles (eq 1). ${ }^{3}$ It has also been shown that various groups $(\mathrm{G})$ can undergo 1,2-migration upon alkyne-vinylidene isomerization, as demonstrated by Iwasawa $(\mathrm{G}=\mathrm{Hal}$, $\mathrm{M}=\mathrm{W}),{ }^{4}$ Fürstner $(\mathrm{G}=\mathrm{Hal}, \mathrm{M}=\mathrm{Au}),{ }^{5}$ Katayama $\left(\mathrm{G}=\mathrm{SiR}_{3}, \mathrm{M}=\mathrm{Ru}\right),{ }^{6}$ and Kawakami $(\mathrm{G}$ $\left.=\mathrm{SnR}_{3}, \mathrm{M}=\mathrm{Ru}\right)^{7}$ (eq 2). However, to the best of our knowledge, no examples of synthesis of heterocycles with 1,2-migration of groups other than $\mathrm{H}$ have ever been reported. Thus, we reasoned that development of alternative routes toward heterocycles, which proceed with 1,2group migration, would be desirable, as they would allow for the synthesis of densely substituted molecules. Herein, we wish to report a new Au-catalyzed cascade cycloisomerization of propargylic derivatives of N-containing heterocycles into fused pyrrolecontaining heterocycles. The cascade transformation involves 1,2-migration of silyl-, stannyl-, and even the previously unknown migration of a germyl group, and allows for efficient synthesis of various fused pyrroloheterocycles functionalized at position C-2 (eq 3).<smiles>[Y]O[Na]</smiles>

$X=O, N R, S$

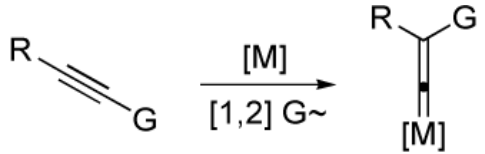

$$
\begin{aligned}
& \text { Iwasawa }(G=\mathrm{Hal}, M=W) \\
& \text { Fürstner }(G=\mathrm{Hal}, M=A u) \\
& \text { Katayama }\left(G=\mathrm{SiR}_{3}, M=\mathrm{Ru}\right) \\
& \text { Kawakami }\left(G=\mathrm{SnR}_{3}, M=\mathrm{Ru}\right)
\end{aligned}
$$

vlad@uic.edu.

Supporting Information Available: Preparative procedures, analytical and spectral data. This material is available free of charge via the Internet at http://pubs.acs.org. 


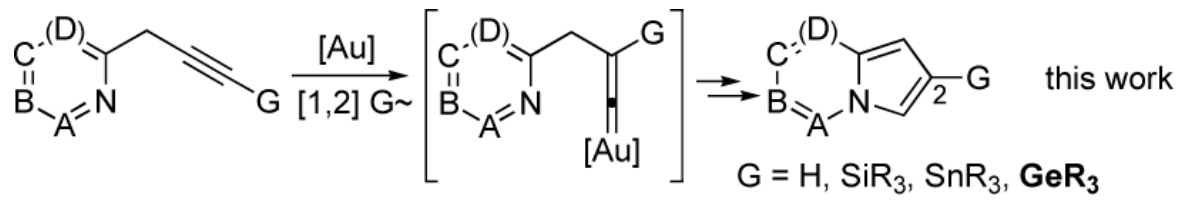

We have recently reported the cycloisomerization of alkynylpyridines into indolizines (eq 4). 8 The reaction proceeds via a base-assisted propargyl-allenyl isomerization to intermediate $\boldsymbol{i}$, followed by its cyclization into the indolizine core. This transformation presumes two formal hydrogen migrations, and thus is limited to the preparation of C-1, 2 unsubstituted indolizines.<smiles>[R]C=CC(C)C=Cc1ccccn1</smiles>

Naturally, as we were interested in developing approaches toward C-1 substituted heterocycles, we turned our attention to the cycloisomerization of easily available ${ }^{9}$ non-conjugated propargylpyridine $\mathbf{1}$ (eq. 5). After catalyst optimization, ${ }^{10}$ it was found that $\mathbf{1}$, in the presence of $\mathrm{Au}(\mathrm{I})$ or $\mathrm{Au}(\mathrm{III})$ salts, ${ }^{11}$ undergoes smooth cycloisomerization into $\mathrm{C}-1$ substituted indolizine $\mathbf{2}$. It is reasonable to propose that this transformation operates through allenyl intermediate $\boldsymbol{i}$ (e.g. via another mode of the propargyl-allenyl cycloisomerization depicted in eq. 4). Alternatively, this reaction may proceed via isomerization of terminal alkyne 1 into gold-vinylidene intermediate $\boldsymbol{v}$, which subsequently cycloisomerizes into the heteroaromatic structure 2 (eq. 5).

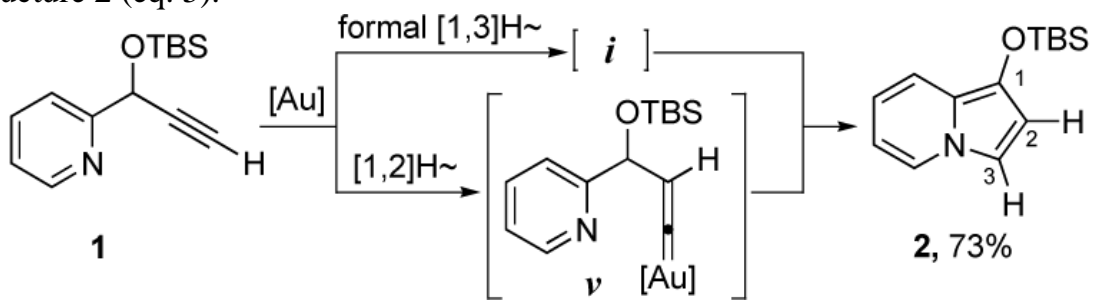

In order to clarify whether this reaction proceeds via an allenyl $(i)$ or vinylidene $(\boldsymbol{v})$ intermediate, we examined cycloisomerization of TMS-substituted propargylpyridine 3a in the presence of Au-catalyst. It was hypothesized that a prototropic isomerization (via intermediate i) ${ }^{12}$ would lead to indolizine with the silyl group attached to the $\mathrm{C}-3$ position, whereas the silyl group would be at C-2 if alkyne-vinylidene isomerization operates (via intermediate $v$ ). To our great delight, it was found that $3 \mathrm{a}$, in the presence of $\mathrm{AuBr}_{3}(2.0 \mathrm{~mol} \%)$ in toluene at $50^{\circ} \mathrm{C}$, underwent smooth cycloisomerization to afford indolizine $\mathbf{4 a}$ with TMS group migration to the $\mathrm{C}-2$ position, as the sole regioisomer in $63 \%$ yield (Table 1, entry 1 ). It deserves mentioning that in indolizines, the $\mathrm{C}-2$ site is an unfunctionalizable position, and its substituent has to be introduced prior to cyclization. 13

Motivated by the importance of differently substituted fused pyrroloheterocycles, ${ }^{14}$ and encouraged by the successful cycloisomerization of TMS-containing substrate $\mathbf{3} \mathbf{a}$, we examined various propargyl heterocycles in this transformation (Table 1). Gratifyingly, the stannyl group, known to undergo migration upon alkyne-vinylidene isomerization ${ }^{7}$ (entry 2), underwent smooth migration to give 2-stannyl indolizine $\mathbf{4 b}$ in good yield. Remarkably, we also found that unprecedented 1,2-germyl migration can also occur to produce 2germylindolizine $\mathbf{4 c}$ in excellent yield (entry 3 ). Notably, this cycloisomerization appeared to 
be general with regard to the heterocyclic core. Other heterocyclic systems, such as isoquinoline (entry 5), quinoxaline (entries 6 and 7), pyrazine (entries 8 and 9) and thiazole (entry 10), reacted smoothly, producing fused pyrroloheterocycles in good to excellent yields.

We propose the following mechanistic rationale for this novel transformation. First, isomerization of alkyne 3 results in the formation of vinylidene $v^{15}$ (Scheme 1), followed by nucleophilic attack of the nitrogen lone pair at the vinylidene carbon, resulting in formation of zwitterion 5. The latter can either undergo a series of 1,2-hydride shifts (Path A), or a deprotonation-protonation sequence (Path B) to furnish $4 .{ }^{16}$ In order to verify which mechanism operates, we performed a deuterium-labeling experiment utilizing isotopically homogeneous propargyl pyridine 3k. It was found that under standard cycloisomerization conditions, the reaction produced indolizine $\mathbf{4 k}$ with equal distribution of deuterium between positions C-2 and C-3, ${ }^{17}$ thus strongly supporting Path A. ${ }^{18}$

In summary, we have developed a new mild cascade cycloisomerization of propargyl $\mathrm{N}$ containing heterocycles into various types of $N$-fused pyrroloheterocycles in the presence of gold catalyst. The reaction proceeds via alkyne-vinylidene isomerization with concomitant 1,2migration

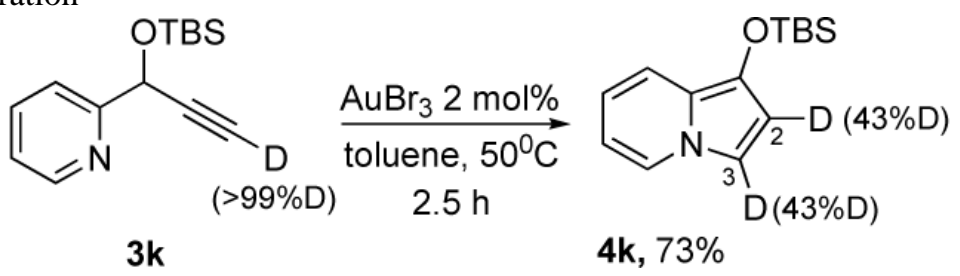

of $\mathrm{H}$, silyl-, and stannyl groups, as well as previously unknown 1,2-migration of a germyl group, giving easy access to a variety of C-2 functionalized heterocycles.

\section{Supplementary Material}

Refer to Web version on PubMed Central for supplementary material.

\section{Acknowledgment}

The support of the National Institutes of Health (GM-64444) and National Science Foundation (CHE 0354613) is gratefully acknowledged. We also thank Mr. Alex Schammel for technical help.

\section{References}

1. For recent example, see: Grotjahn DB, Zeng X, Cooksy AL. J. Am. Chem. Soc 2006;128:2798. [PubMed: 16506748]

2. For reviews, see: a Wakatsuki Y. J. Organomet. Chem 2004;689:4092. b Bruneau C, Dixneuf PH. Acc. Chem. Res 1999;32:311. See also: c McDonald, F. E. Chem. Eur. J 1999;5:3103.(d)

3. See, for example: a McDonald FE, Gleason MM. J. Am. Chem. Soc 1996;118:6648. b McDonald FE, Burova SA, Huffman LG. Synthesis 2000:970.

4. Miura T, Iwasawa N. J. Am. Chem. Soc 2002;124:518. [PubMed: 11804472]

5. Mamane V, Hannen P, Fürstner A. Chem. Eur. J 2004;10:4556.

6. Katayama H, Wada C, Taniguchi K, Ozawa F. Organometallics 2002;21:3285.

7. Shirakawa E, Morita R, Tsuchimoto T, Kawakami Y. J. Am. Chem. Soc 2004;126:13614. [PubMed: 15493908]

8. Kel'in AV, Sromek AW, Gevorgyan V. J. Am. Chem. Soc 2001;123:2074. [PubMed: 11456838]

9. See Supporting Information for details. 
10. Employment of $\mathrm{Cu}(\mathrm{I})$ salts led to trace amount of products, whereas various $\mathrm{Ag}, \mathrm{Pt}$, and $\mathrm{Pd}$ sources tested did not catalyzed this reaction at all. ${ }^{9}$

11. For recent reviews on Au-catalyzed reactions, see: a Hoffmann-Röder A, Krause N. Org. Biomol. Chem 2005;3:387. [PubMed: 15678171] b Hashmi ASK. Gold Bull 2004;37:51. For Au-catalyzed synthesis of heterocycles, see: c Hashmi ASK, Schwarz L, Choi J-H, Frost TM. Angew. Chem. Int. Ed 2000;39:2285. d Yao T, Zhang X, Larock RC. J. Am. Chem. Soc 2004;126:11164. [PubMed: 15355093] e Zhang L, Kozmin SA. J. Am. Chem. Soc 2005;127:6962. [PubMed: 15884934] f Hoffmann-Röder A, Krause N. Org. Lett 2001;3:2537. [PubMed: 11483054] g Sromek AW, Rubina M, Gevorgyan V. J. Am. Chem. Soc 2005;127:10500. [PubMed: 16045332] h Gorin DJ; Davis NR, Toste FD. J. Am. Chem. Soc 2005;127:11260. [PubMed: 16089452] For Au-catalyzed carbocyclizations, see for example: i Fürstner A, Hannen P. Chem. Commun 2004:2546. j Shi X, Gorin DJ, Toste FD. J. Am. Chem. Soc 2005;127:5802. [PubMed: 15839674] k Luzung MR, Markham JP, Toste FD. J. Am. Chem. Soc 2004;126:10858. [PubMed: 15339167] 1 Zhang L, Kozmin SA. J. Am. Chem. Soc 2004;126:11806. [PubMed: 15382911] m Nieto-Oberhuber C, Lopez S, Echavarren AM. J. Am. Chem. Soc 2005;127:6178. [PubMed: 15853316] See also: n Asao N, Takahashi K, Lee S, Kasahara T, Yamamoto Y. J. Am. Chem. Soc 2002;124:12650. [PubMed: 12392398] o Shi Z, He C. J. Am. Chem. Soc 2004;126:5964. [PubMed: 15137751] p Zhang L. J. Am. Chem. Soc 2005;127:16804. [PubMed: 16316224] See also ref. ${ }^{5}$.

12. For Au-catalyzed propargyl-allenyl prototropic isomerization, see ref. $11 \mathrm{c}$.

13. For review, see for example: Behnisch R, Behnisch P, Eggenweiler M, Wallenhorst T. "Indolizine". Houben-Weyl E6a/2a 1994:323.

14. For pharmacologically important indolizines, see, for example a Hagishita S, Yamada M, Shirahase K, Okada T, Murakami Y, Ito Y, Matsuura T, Wada M, Kato T, Ueno M, Chikazawa Y, Yamada K, Ono T, Teshirogi I, Ohtani M. J. Med. Chem 1996;39:3636. [PubMed: 8809154] b Schoeffter P, Hoyer D. Naunyn-Schmiedeberg's Arch. Pharmacol. 1989;339:675. [PubMed: 2770889] c Gundersen L-L, Malterudb KE, Negussiea AH, Risea F, Teklua S, Østby OB. Bioorg. Med. Chem 2003;11:5409. [PubMed: 14642585]

15. $\mathrm{Au}(\mathrm{I})$ is most likely the active catalyst. In the case of employment of $\mathrm{AuBr}_{3}$ as a precatalyst, the latter can be reduced to $\mathrm{Au}(\mathrm{I})$ species via various redox processes. See ref ${ }^{11 \mathrm{~b}}$ for discussion.

16. A referee pointed out possible Au-catalyzed C-3 $\rightarrow$ C-2 TMS group migration after cyclization, and brought to our attention a reference on Aucatalyzed migration of alkyl group in indole series: Alfonsi M, Arcadi A, Aschi M, Bianchi G, Marinelli F. J. Org. Chem 2005;70:2265. [PubMed: 15760214] However, a test experiment with pyrroloquinoxaline 8, C-3 TMS analog of 4g, ruled out this possibility. ${ }^{9}$

17. Control experiment indicated no deuterium scrambling between $4 \mathrm{~h}$ and $\mathrm{D}_{2} \mathrm{O}$ occurred under the same reaction conditions. ${ }^{9}$ For deuterium scrambling in $\mathrm{N}$-unsubstituted pyrrole ring in the presence of $\mathrm{Au}(\mathrm{I})$ complexes, see ref $11 \mathrm{~h}$.

18. Equal distribution of deuterium between positions $\mathrm{C}-2$ and $\mathrm{C}-3$ is possible via Path $\mathrm{A}$ if there is no H/D kinetic isotope effect (transformation 6 to 4). Obviously, Path B cannot explain the observed scrambling of deuterium at C-2. 
<smiles>[R]C([B])(C#CO)c1ccccn1</smiles>

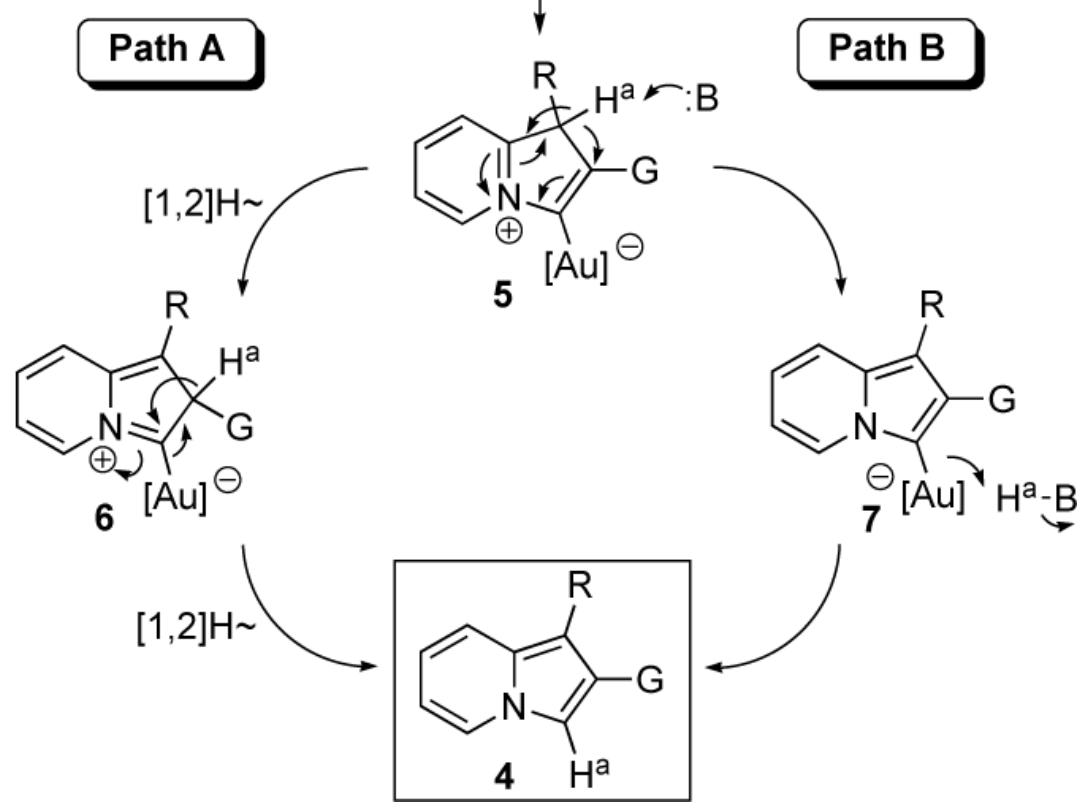

Scheme 1.

Proposed Mechanism for Cascade Cycloisomerization 


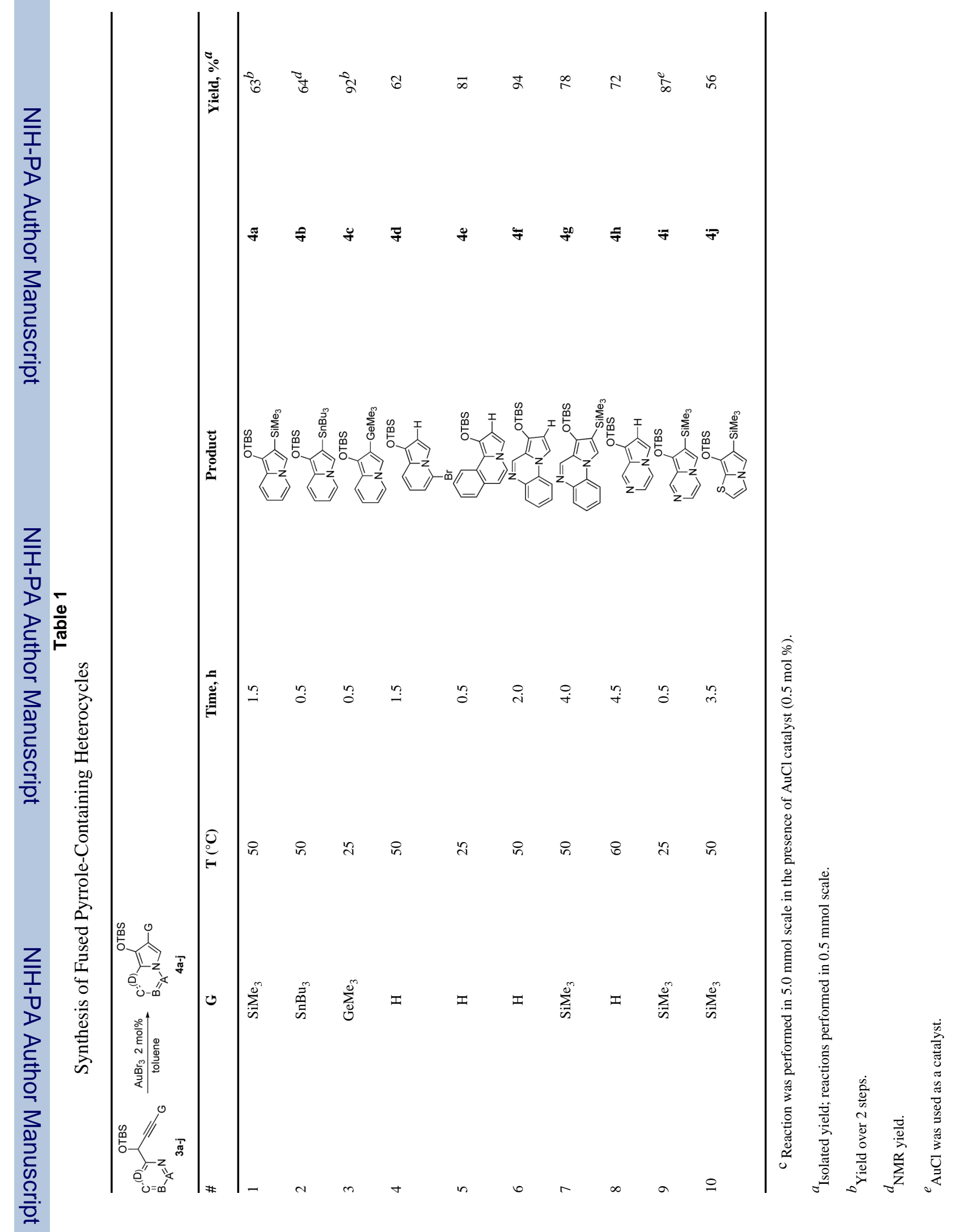

